\title{
The Application of Sustainable Materials in Contemporary Jewelry
}

\author{
Yue Zhou, Xing Fang
}

\author{
School of Art and Design, Wuhan University of Technology 430000, China
}

\begin{abstract}
Keywords: sustainable materials, contemporary jewelry, design methodology
\end{abstract}
\begin{abstract}
With the combination of modern art and jewelry media, contemporary jewelry is rising rapidly in Europe and America. It is no longer confined to precious metal and stones as working material, paper, wood, waste plastics and other cheap things are more and more designed for jewelry. Today, human is facing severe environmental degradation, such as global warming, desertification, biodiversity destruction, the meaning of sustainable jewelry design becomes more and more valuable than the simple creative and artistic practice, but questioning the mining needs of precious metals and precious stones in the field of jewelry industry, and challenging the status of luxury in the commodity economy. Under such background, this article aims to analyze the unique design method of sustainable jewelry.
\end{abstract}

\section{Introduction}

"Sustainable materials", also known as "green materials", refer to materials that take into account of the energy consumption and pollution emissions of the material throughout the life cycle (production, use, recycling). Today, the non-toxic, renewable, low energy consumption, recyclable material [1] had been widely used in urban architectural design and product design, and formed "green design" trend. Jewelry as the most minimal compression of the aesthetic theory [2], inevitably affected by this new concept, and jewelry following this creation idea add a touch of green for contemporary jewelry design. On the other hand, jeweler are trying to use more sustainable material to change the impression of jewelry as gold, silver and precious things. Their attempt are building jewelry's art language constructively. The main purpose of this paper is to analyze the cultural context in sustainable jewelry, and discussing its design method.

\section{Design Methodology}

\subsection{Old to New}

By replacing, adding or reducing the elements of the original accessories, designer can usually give the old jewelry a new content and appearance as a second life. Its greatest feature is the renewed jewelry inherited parts of the old jewelry's physical characteristics and emotional memory, but the function and concept are put more in line with the needs of the current wearer. Through this "improvement", jewelry is to obtain the value and significance of regeneration.

Now the modern jewelry designers continue to use the "redesign" method which based on the transformation of the shape and pay more attention to give jewelry a new concept. Dutch designer Gijs Bakker designed the "real" series of jewelry (Fig 1). on the shiny but tacky structure, by replacing some rough artificial gemstones by real diamonds and sapphire, Gijs successfully mixed noble and humble together like heaping ridicule on the jewelry's evaluation standard. Moreover the designer also create a special aesthetic experience by arranging real and artificial gems paralleled. But on the other hand, we must rethink the successful reason of this work. If there is no aura of real gems, will this piece been seen as art works any more? And is that means gems still plays an important role in the art jewelry? 


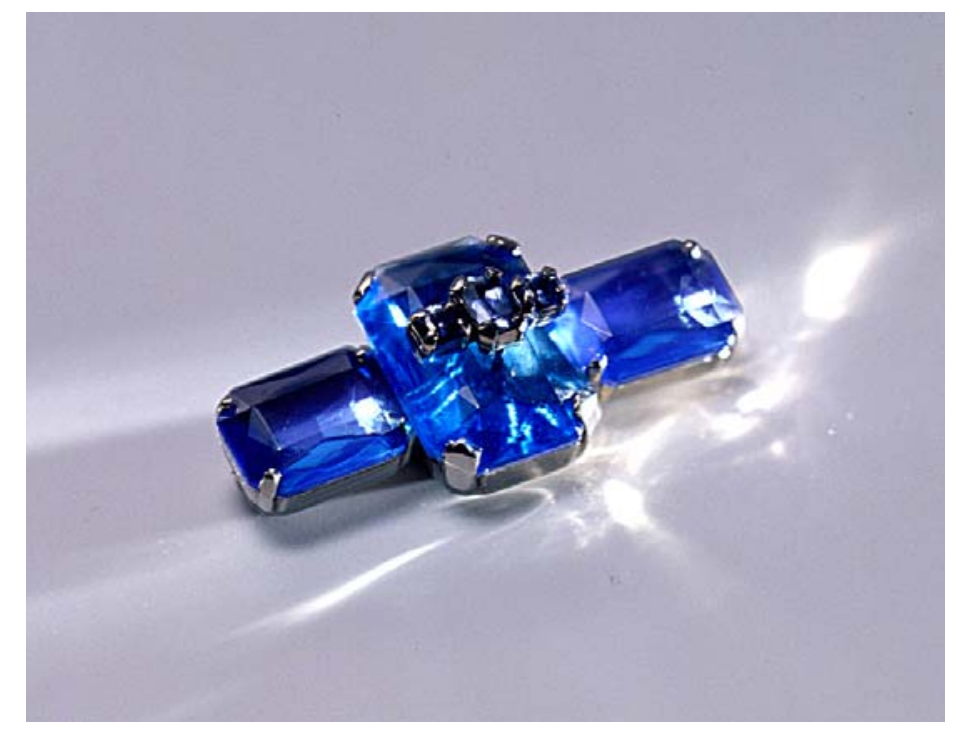

Figure 1: Blue Sea Brooch Material: Platinum, Sapphire, Plastic, Metal 2004

The section headings are in boldface capital and lowercase letters. Second level headings are typed as part of the succeeding paragraph (like the subsection heading of this paragraph). All manuscripts must be in English, also the table and figure texts, otherwise we cannot publish your paper. Please keep a second copy of your manuscript in your office. When receiving the paper, we assume that the corresponding authors grant us the copyright to use the paper for the book or journal in question. When receiving the paper, we assume that the corresponding authors grant us the copyright to use the paper for the book or journal in question. When receiving the paper, we assume that the corresponding authors grant us the copyright to use.

\subsection{Waste to Treasure}

This design method is similar to "old to new", since they are both getting the new features and forms by remodeling of old items, but there is still difference between them. Here the design object is mainly anti-biodegradable materials including plastic bags, old tires, industrial waste and so on. Designer can use a series of technique like sewing, ironing, welding, knitting, and soldering to change waste material into splendid accessories. "Waste to Treasure” and Green Design are the same method of come down in one continuous line, and the most important feature is reducing energy costs, hand-made, achieving environmental and ecological requirements. The designer are been asked to maximize the beauty of the material according to the texture and characteristics of waste by choosing accurate technology. For example, the used packing tape can be knitted as Chinese or Japanese knot, and the metal mesh can be combined with embroidery pattern, and sometimes you can even add other materials to modify as embellishment.

After the 1980s, the use of waste in Contemporary jewelry was increasing. Interestingly, people found that compared to prudent metalwork, the design of waste was like a free game, since the

funny designing method and endless creative idea could make contemporary jewelry designers, wearers and viewers are all fascinated. Dorothy Hogg designed "Sackler Center" Jewelry based on the fruit packaging - the plastic mesh sets, since its diamond-shaped network structure is the obvious meaningful form to redesign. Hogg cut the net into the ring size, and connected both nodes to form the ring. In the end of making, she placed a gem in the net brightly. The net cell is just the correct size that allow people to see the gem, but not let prevent the gem from leaking out. This distinctive design is like asking people to see only half face of beauty which will make them fantasy the whole picture for a long time. From the functional point of view, the elasticity of net is suitable for different finger sizes, and eliminating the need to customized. 


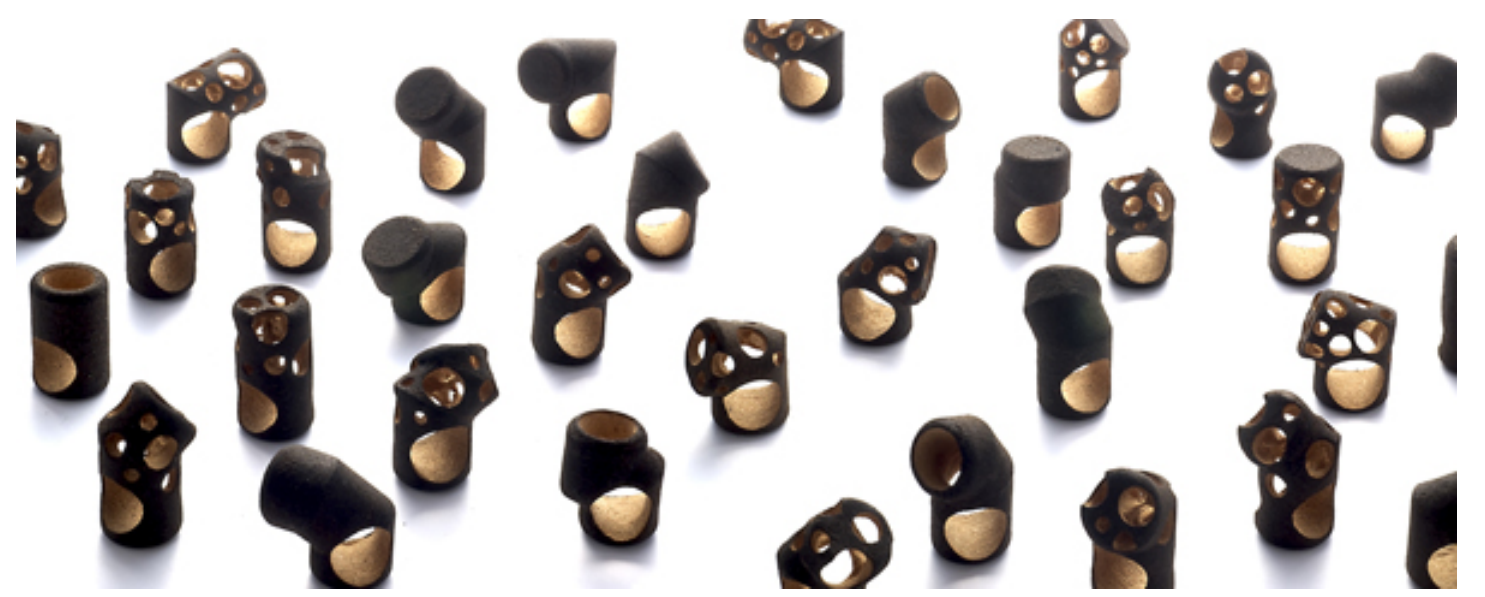

Figure 2:"Kanpai" rings Meterial: wine cork, metal 2008

Japanese designer Emiko Suo has a series of designs on the bottle cork. Through the complex process like the hollowing, grinding, reorganization and coloring, some corks had some cheese-like holes, and others were like osteotomy and pipe. According to these recreated shape, Suo made some necklaces and rings. She named one of the necklaces "Kanpai"(Fig 2). The name is not only a direct instruction, but also given the works a set of short-film memory and narrative value. The audience can imagine Suo's working process of collecting material from friends' party to redesigning these cork, so people can feel the whole beauty of redesign in reality.

In addition, the diversified materials are widely accepted in the design of jewelry, so that some designers and artists, like sculptors, painters or potters from different educational background can also participate in the study of modern jewelry. Because there is no rich metalworking technology, so they often use other technologies for processing the waste. "In the mid-20th century, most of the pioneers of modern jewelry designers are graduated from other professional, but through self-study or short-term training, they can master the jewelry technology" [3]. By absorbing hundred different techniques and concepts, those cross-border designer made a new look of contemporary jewelry.

\subsection{Made the Best Use of Things}

In 2011, the artist Song Dong held a solo exhibition of the same name as "make the best use of things" in New York, showing a total of 10,000 items like the soap, broken toys, Pots and pans accumulated by his mother Ms. Zhao Xiangyuan in the past few decades. These things filled with a large exhibition hall, that the viewer can not help but think of a person's daily necessities is so much even in the era of material scarcity. And compared to today, people's consumption is not commonly referred to material practice, but the symbolic value of consumer goods. Because by judging the consumption behavior and brand logo, people established differences social stages in these consumption process. Under the effect of vanity, people continue to consume and occupy more or even non-essential products. Song Dong's works allow people to reflect on the excessive material consumption, and questioning how can designer change this desperate situation controlling by greedy, vanity and apathy.

In life, these daily necessities can be easily found at home like pegs, buttons, bulbs, cups, chopsticks, toothbrushes, hair rope and so on. Because they are numerous and messy, people usually leave things idle. For these materials, jewelry designers can also use to create accessories. In the design process, the designer needs to use other technology to trim or increase some elements to improve the wearing function and aesthetics.

German artist Eilean Somnitz turned the clothes pegs into the rings, and she used the elasticity of the clip to set a man-made gem on the top. So pegs, as if by magic, from boring necessities into gorgeous jewelry. Min-ji Cho designed a series of ornaments based on rubber gloves. Benefits from different color and knit techniques, she created the unique style that cross the boundary line of the precious jewelry material. Manuela Sousa's match brooch is discharged from a root match for heart-shaped. When people wear the brooch, the matches are just above human heart. Like "object"(Fur-covered cup, Saucer and spoon) created by Oppenheim Meret, Manuela's work creates a surrealist moment that the matches are burning, and those heat and light are filled with warm feeling. 
In the era of consumerism, "make the best use of things" has a very positive practical significance. Not only saving the resources, but also people can redefine the existence of daily necessities, and dig out the aesthetics under the tacky appearance. Compared with fine metal-works, these accessories are supported by DIY techniques and thrifty Home philosophy which can be easily understand by non-professionals.

\subsection{Take Virtual as Real}

The so-called "take virtual as real " refers to the jewelry is released from physical existence by light, dust, slide projection, body stamp and other nonphysical media. However without any traditional media, these virtual way can still create beautiful pattern on human body, and since these pattern are always short-lived, designers usually need to record their design process as a picture or video.

British designer Tiffany Parbs has been committed to representing the relationship between jewelry and human body. Her designs often presented the skin as a performance material by using outstanding ways. The "baking" project is through the sun exposure, so that the letter"raw"could appear on the body. Perbs was making a pun here, as "raw" can both indicated the natural of skin and clean of technique. The "extraordinary" series of jewelry designed by Azumi and David also embodies the concept of "take virtual as real", and they used stamp with special designed pattern and ink to decorate human body. Some pattern are designed as diamond and some as watches imprinted on the neck and wrist. Those 2D patterns remind people of the real gem necklaces and watches, but They can be erased soon.

\section{Summary}

Although jewelry made from sustainable materials will cause people a lot of confusion. Is the light and shadow produced by the projection a real jewelry? If jewelry had no economic value, then what is the meaning of purchase? But we have to understand that jewelry is the hybrid with lots of social functions [4], like presenting social stage and wealth, expressing personal aesthetics, attracting opposite sex and so on. Those functions are connected closely with our culture, and when our culture embraced the new technology and new aesthetics, the only way jeweler can do is to make traditional jewelry catch up this trend.

\section{References}

[1]. Kang Hui 1, Li Jing 2. The Study of Sustainable Green and Conceptual Design [J] China Packaging Industry, 2013,16: p.85.

[2]. Bort. Hamlin. The Principle of Architectural Form Beauty [M]. Beijing: China Construction Industry Press, 1982, p.56.

[3]. Kelly L'Ecuyer, Michelle Finamore. Jewelry by Artist: In the Studio, 1940-2000 [M]. Boston: MFA Publication, 2010, p.18.

[4]. Graham Hughes. The art of jewelry: a survey of craft and creation [M]. UK: Viking Press, 1972, p.12. 